\title{
SURVIVAL PERIODS IN TRAUMATIC TETRAPLEGIA
}

\author{
By A. G. HARDY, M.B.E., M.A., B.M., F.R.C.S. \\ Spinal Injuries Unit, Lodge Moor Hospital, Sheffield, England
}

ThE Spinal Injuries Unit in Sheffield admitted 33I new cases of traumatic quadriplegia in the period 1948 to 1972 inclusive. These cases were analysed and placed into groups which took into account a number of features which were eventually condensed under three main headings:

I. Age at time of injury.

2. Time of admission to hospital after injury.

3. Degree of spinal cord injury as to whether complete or incomplete.

A meaningful statistical analysis of these cases as strictly comparable with those of the normal life expectation tables of Insurance Companies or the mortality figures of the English Registrar General is not considered a practical proposition mainly because of the breakdown of the figures into very small units. A further difficulty presented because of the short period of observation (namely 25 years), and also because over 200 of the cases were admitted in the last ten years of the 25-year period. The rising incidence of traumatic quadriplegia means that there has been insufficient time to observe a sufficient number of cases over a prolonged period. For this reason I have produced graphs which illustrate the factual situation and indicates the size of the sample of cases which are available for further study during any one period after the time of accident. The graphs are drawn with the assumption that all the accidents happened on the same day and thus the sample of those who survived a year is obviously very much larger than those who have survived ten or more years. Most of the cases were admitted within a matter of days from injury, the main exceptions to this being in the group of cases with incomplete types of quadriplegia. Cases of complete quadriplegia are defined as those having no sensory or motor recovery below the level of the spinal cord injury while cases of incomplete quadriplegia are those showing both motor and sensory recovery below the level of the spinal cord lesion. This group presented with a wide variety of useful function ranging from minimal activity to major recovery in all systems. No attempt has been made to classify these into sub-groups which would obviously be necessary to compare like with like.

Figure I shows the course of events in 30 cases of complete quadriplegia who were over 45 years of age at the time of their accident. Twenty-nine have died in the past 25 years; 12 within a week; four more within a year and 13 within seven years. The one survivor in the present series is still living I I years after the accident which he sustained when he was 46 years old.

Figure 2 shows the progress of 125 cases of incomplete quadriplegia who were also more than 45 years of age at the time of accident. The degree of incompleteness ranged from minor sparing of long tract function to major motor and sensory recovery in all systems. Sixty-three have died; 12 within one week; 

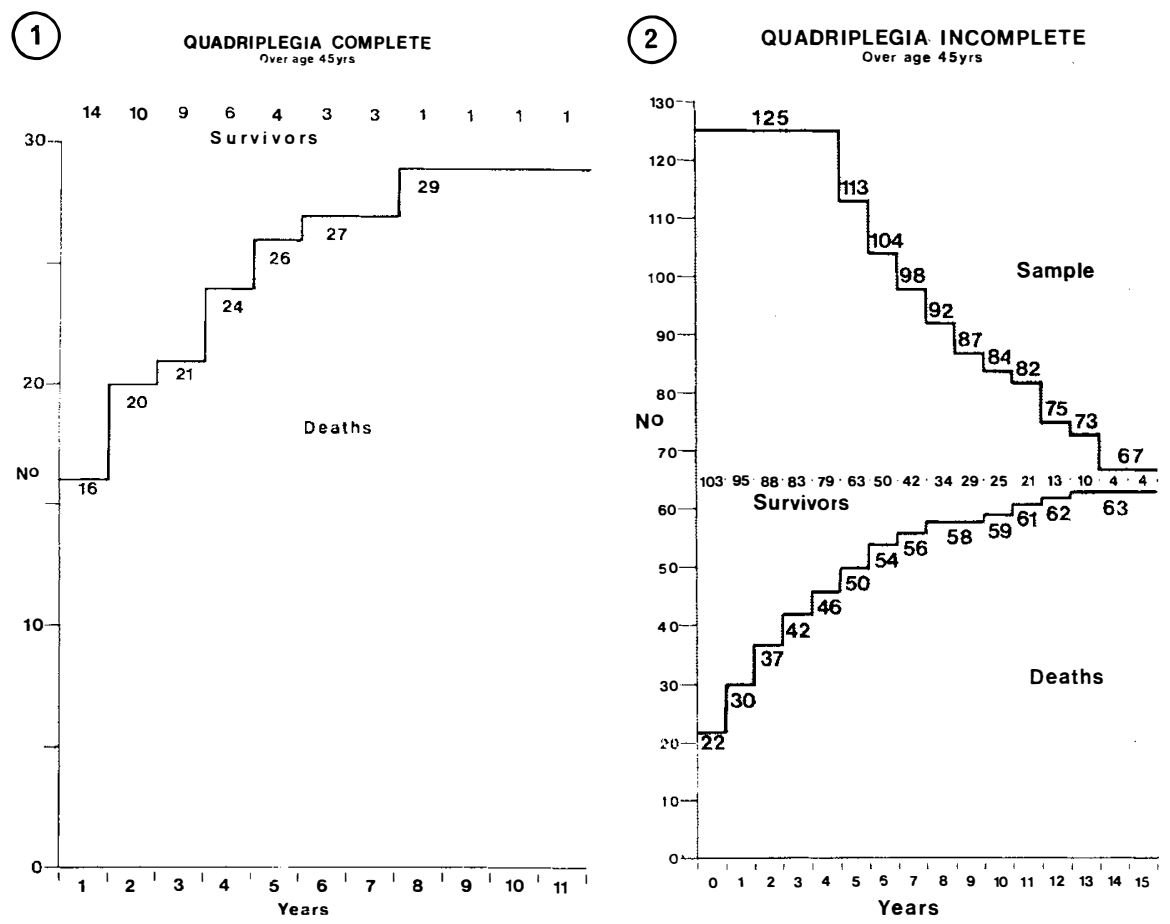

(3) QUADRIPLEGIA COMPLETE

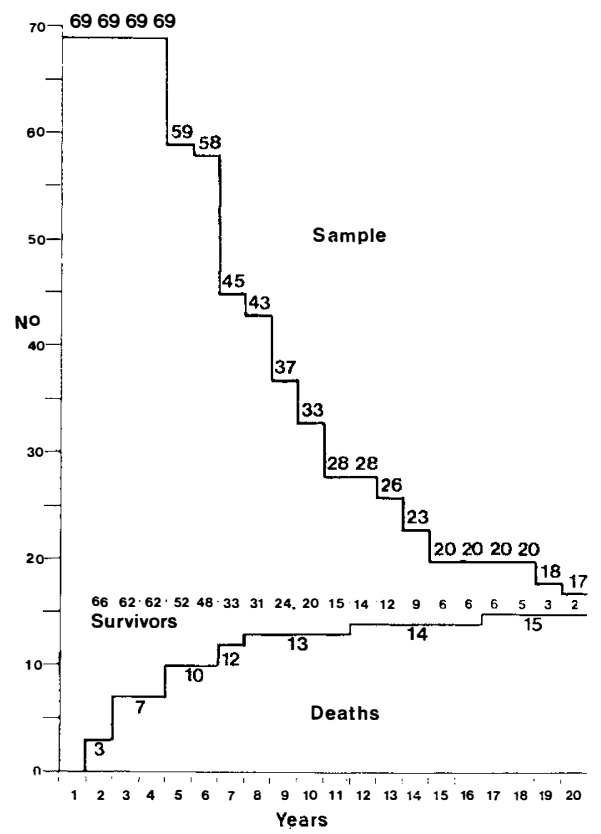

(4) QUADRIPLEGIA INCOMPLETE

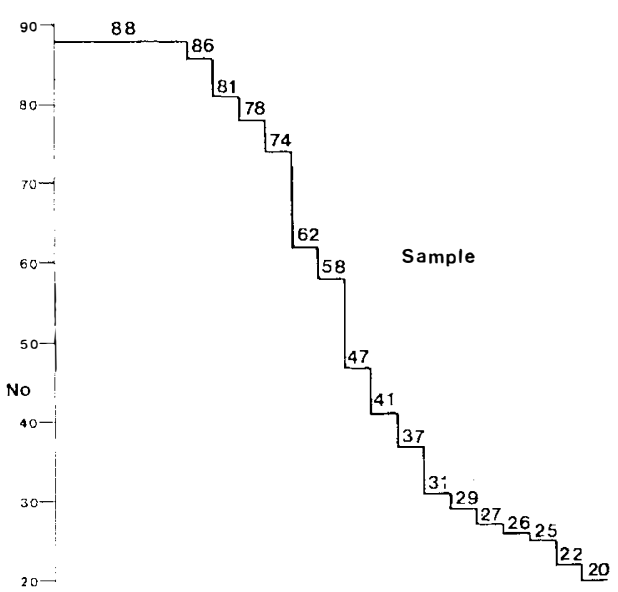

$\begin{array}{lllllllllllllllllllll}88 & 88 & 88 & 87 & 87 & 84 & 79 & 76 & 71 & 58 & 54 & 43 & 37 & 33 & 27 & 24 & 22 & 20 & 19 & 16 & 14\end{array}$ Survivors

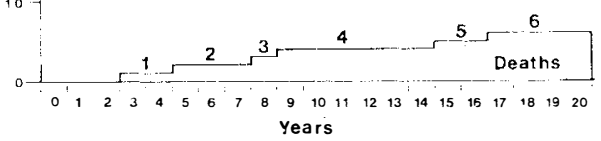




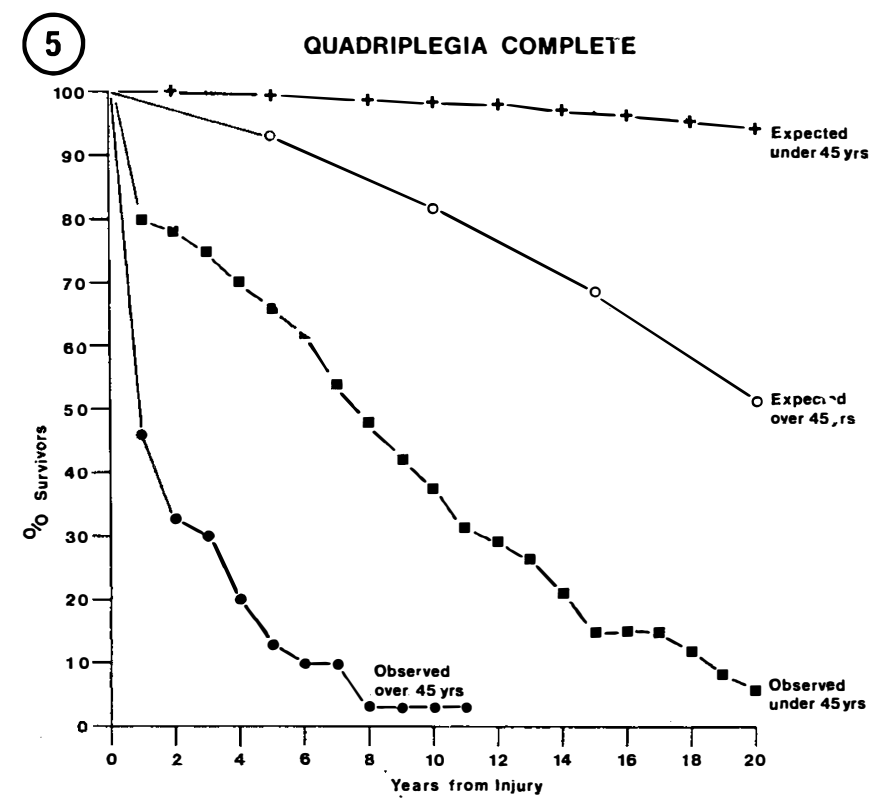

I2 more within one year and $4 \mathrm{I}$ in the next $\mathrm{I} 2$ years. Sixty-two have survived for varying periods which can be identified on the graph where it can be seen that 25 out of 84 have survived ro years and four out of 67 for I6 years, with the possibility of more surviving for a similar period. Note should be made of the flattening of the curve of incidence of deaths as the survival periods get longer.

Figure 3 shows the cases of complete quadriplegia who were under 45 years of age at the time of accident. There were actually 88 cases in this group. Ten died within one week and a further nine within the next three months and are not shown in the graph. Fifteen more died within the next 17 years.

There are 54 survivors of whom I 4 out of 28 have survived 12 years and two out of $\mathrm{I} 7$ have reached 20 years and are likely to be joined by others who sustained accidents more recently and still survive.

Figure 4 represents the pattern of events in a group of 88 cases of incomplete quadriplegia who were under 45 years of age at the time of accident. There were no early deaths in this group but this was the group that contained more cases of late admission than in any other group and it is significant that early deaths occur in the first days or weeks after injury. It is also significant that the patients were young and a high proportion in the second and third decades of life. Only six have died in the 20-year period. Eighty-two survive and 54 out of 58 have reached ten years and 24 out of 29 have survived I5 years while I4 out of 20 have survived 20 years and are likely to be joined by others from samples of more recent years.

Figure 5 is a more conventional graph showing the comparison between the expected and observed experiences of comparable age-groups. The expected line tracing is obtained from figures published by the Registrar of births and deaths and the original graph recorded deaths per thousand of the general population. For the purposes of this paper all figures have been reduced to percentages. 


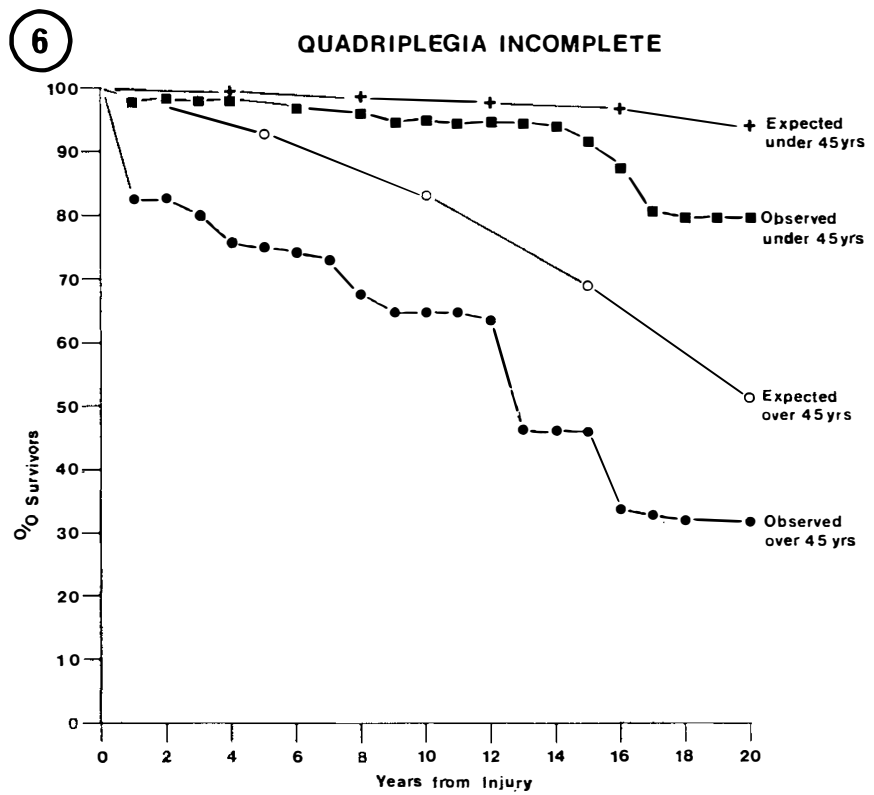

Cases of complete quadriplegia in the age-groups above and below the age of 45 years are shown on the same graph together with the expected survival period of a corresponding sample from the normal population. Deaths in the first year after accident have a major influence on the tracing and thereafter there is a steady but smaller loss each year but still significantly below that of the normal population.

Figure 6 is a similar graph taken from the figures for cases of incomplete quadriplegia and compared with those of the normal population. As anticipated, this graph shows the tracings to be much closer together in the earlier years of survival and then further apart in the later periods.

It will be important to correlate the causes of death with these experiences and to identify those situations which influence both early death or long survival. The exclusion of deaths in the first three months greatly enhances the survival statistics.

\section{SUMMARY}

The survival periods in 33I cases of quadriplegia are reviewed. Important features are degree of injury, age at time of accident and ability to survive the first three months. A comparison of comparable circumstances is essential if we are to correctly interpret our respective mortality rates.

\section{RÉSUMÉ}

On étudie les périodes de survie de 33 I cas de quadriplégie. Parmi les caractéristiques importantes, on trouve le degré de la lésion, l'âge au moment de l'accident et la capacité de survie pendant les trois premiers mois. Il est essentiel de comparer des circonstances comparables si nous voulons interpréter correctement nos taux de mortalité successifs. 


\section{ZUSAMMENFASSUNG}

Die Überlebens-Periode wurde in 33I Fällen überprüft. Wichtige Faktoren sind die Schwere des Unfalls, das Alter zur Zeit der Verletzung und die Fähigkeit, die ersten drei Monate zu überleben. Ein Vergleich vergleichbarer Umstände ist wichtig für eine korrekte Interpretation von Sterblichkeitsraten.

\section{Discussion}

Dr Cheshire (U.S.A.). Mr Chairman, I have an ethical, moral, professional and a legal dilemma. We have heard three papers which make one point abundantly clear and that is the chances of survival of a 60-year-old person who becomes completely tetraplegic are very very bad. Now, with what I am concerned is the quantity of life or the quality of life. I personally have on no occasion had experience of one of my patients, 70 years of age or greater, with complete tetraplegia, surviving for more than one year. What am I doing for these patients by assisting them to survive the first three months of the acute illness to go into a nursing home and die in that nursing home within the next nine months? I do not want to bring the sordid subject of money into it. What I think I am really doing is agonising within myself as to how hard should I try to preserve the life of a person who I am confident to the best of my knowledge has a complete tetraplegia and the patient is more than 60 years of age? I am hoping to learn, I do not know the answer.

DR A. G. HARDY (G.B.). I have presented these figures in tetraplegia not with any particular pride and not with any particular horror. Naturally, this is what happened, they are the facts. These figures in the mortality of my older tetraplegics are those in which we did not for instance consider positive pressure and ventilation. All I am saying is this is what happened and we have one survivor out of that group. But it is true that we had several who survived three or four years. Now, whether that is a quality of life which you are talking about, I hesitate to say.

ChaIRman. I was just going to say that this is an ethical, medical, moral, philosophical problem, and each of us has to take his own responsibility.

DR F. W. MEINECKe (Germany). The three papers, as I understood, are dealing with tetraplegics only, and I know that these are the most complicated group we ever have. But by the insurances and by law we are also asked what about life expectancy in the dorsal and lumbar lesions. I consider this will be quite different from what we heard this morning, and therefore I would like to ask the three speakers if they can give us any ideas about life expectancy as seen in their cases of dorsal and lumbar lesions.

DR WATSON (G.B.). One cannot generalize for the whole world. It so happens that in the industrial Midlands of this country people live in little houses and they have bedrooms upstairs and often the toilet is just outside the back door. These old ladies have to get up in the middle of the night. It is quite surprising how many of them fall downstairs when visiting friends. In other words, they are not too bad in their own homes but when they go and live with their son or their daughter or some relative and they get up in the night to go to the toilet (the main time that the accidents occur), they take the wrong turning and do not know where the light switch is. It is quite common to find that they have their accident at their friend's or their son's home. But it is very, very difficult-you cannot take an old person out of a house that they've lived in for so many years-they like their own home and they refuse to leave it. I do not think there's any answer to this.

Dr H. L. Frankel (G.B.). The question about the non-tetraplegic-I think it is no coincidence that Dr Hardy and I both chose to look at tetraplegics. We had one year to do it and we thought that we would like to get some real life-expectancy figures out of it. We haven't quite succeeded. We've chosen to look at a similar group and we're nearly there. I think in another ten years we could give a completed table. At the same time, we have been collecting all the others but we have not yet analysed them. Looking 
at the crude death rate there is no doubt whatsoever that mortality of the dorsal and lumbar cases is significantly higher than the general population and also there is no doubt that it is significantly less than the cervicals. But I cannot give you figures in years at the moment.

DR A. H. HARDY (G.B.). I share this view. We have also carried out analysis of the paraplegics complete and incomplete and the patterns are as Dr Frankel has said. Undoubtedly we have very long surviving periods and there are going to be more, but there's still going to be a greater fatality than in the normal population.

DR L. S. Michaelis (G.B.). I do not know whether I am alone in feeling a little lost between the various data and starting-points which have been taken for these statistics and you have heard excellent statistics from the two senior centres in this country. Now imagine that in the next 20 years we shall get several statistics from various centres in various countries, and if they too use different basic starting-points we shall be completely confused. May I make a plea that first of all our three speakers put their heads together and try to analyse their collective cases according to one prestandard: for example, that they leave out those which they consider to be early death -in one statistic it was up to ten days, in another statistic it was up to three months, or within three months. This confuses us and doesn't give us comparable statistics. May I once more, and I have done so before, make a plea that we should pool information and that we should publish together the collective numbers from a variety of centres according to one and the same scheme, laid down according to the various points of view. Only then shall we get information which we, the doctors concerned in this field, and the lawyers concerned with our patients or former patients, will really understand and be able to advise them.

ChaIRman. Thank you, Dr Michaelis, I think you are absolutely right and I would strongly agree with what you are saying. 